\section{Ornithine Decarboxylase Inhibitors of Microbial Origin A Possible Approach for Screening of Antitumor Agents}

\author{
Akiko Fujiwara, Yoshihiko Shioml, \\ Ken Suzuki and Mitsuhiko FuJTwara \\ Nippon Roche Research Center, \\ Kamakura, Kanagawa, Japan
}

Received February 8, 1978

Numerous literatures have provided many indications of important role for polyamines as regulators of cell proliferation in a variety of non-neoplastic and neoplastic tissues, including embryos, regenerating livers, hormone stimulated cells and tumor cells. ${ }^{1-5)}$ Ornithine decarboxylase (EC 4.1.1.17, L-ornithine carboxylyase; $O D C$ ) is the rate limiting enzyme in polyamine biosynthesis which catalyzes the first step in the pathway, the formation of putrescine from ornithine. Hence, it is reasonably postulated that specific inhibition of $\mathrm{ODC}$ would lead to inhibition of rapidly proliferating cells such as cancer cells. Although a wide variety of enzyme inhibitors have been screened for the antitumor activities, ODC has not so far been used as the probe for such screening studies. In this communication we wish to describe in vitro screening system for $O D C$ inhibitors using chick embryo as the enzyme source and some of the results of our screening studies.

Fertilized eggs were hatched at $38 \sim 39^{\circ} \mathrm{C}$. Embryos at 7 th day were freed from the extramembryonic membranes and yolk sac, washed with $0.05 \mathrm{M}$ phosphate buffer, $\mathrm{pH} 7.1$, and homogenized in the same buffer with a glass homogenizer (Takashima Manufact. Co.). The homogenates were centrifuged at $100,000 \times g$ for $90 \mathrm{~min}$ and the supernatant fluid was used as crude enzyme preparation. The enzyme activity was quantitatively determined by measuring the liberated ${ }^{14} \mathrm{CO}_{2}$ from DL-ornithine-1-14C (Daiichi Pure Chem. Co.) according to the method described by Russell et al. ${ }^{\text {? }}$ The incubation mixture contained pyridoxal phosphate, $0.1 \mu$ moles; enzyme preparation, $0.5 \mathrm{ml}$; DL-ornithine${ }_{1 .}{ }^{14} \mathrm{C}, 1 \mu$ mole $(0.25 \sim 0.5 \mu \mathrm{Ci})$; culture broth sample (inhibitor) or distilled water, $0.2 \mathrm{ml}$; and $0.05 \mathrm{M}$ sodium phosphate buffer, pH 7.1, to make a final volume of $2 \mathrm{ml}$. Incubation was carried out in a 25-ml Erlenmeyer flask equipped with a rubber stopper supporting a polyethylene center well(Kontes Glass Co./ Natsume Seisakusho) which contained $0.25 \mathrm{ml}$ of mixture of ethanolamine and 2-methoxy-ethanol (2:1). Reaction was started by injecting the enzyme solution to the flasks containing other components of the reaction mixture which were pre-incubated at $37^{\circ} \mathrm{C}$ for $10 \mathrm{~min}$. The reaction was conducted at $37^{\circ} \mathrm{C}$ on a reciprocal shaker (70 strokes per minute) for $60 \mathrm{~min}$. The reaction was stopped by injecting $0.5 \mathrm{ml}$ of $5 \mathrm{~N}$ $\mathrm{H}_{2} \mathrm{SO}_{4}$ into the reaction mixture through a rubber stopper. The mixture was agitated for an additional $60 \mathrm{~min}$ to allow complete absorption of $\mathrm{CO}_{2}$. The center well was then removed, cut off into a vial containing $2 \mathrm{ml}$ of ethanol and $10 \mathrm{ml}$ of toluene with $0.8 \%$ butyl-PBD [2-(4-tert-butylphenyl)-5-(4-biphenylyl) $-1,3,4$-oxadiazole] and assayed for the radioactivity in a liquid scintillation counter (Intertechnique SL-30).

L-Histidine decarboxylase (HDC) activity has been reported to increase in some rapidly growing tissues. ${ }^{2)}$ The assay of the present ODC enzyme preparation from 7-day chick embryo for HDC activity revealed that only negligible HDC activity was present in the preparation.

Addition of the following antimicrobial agents at the concentration of $100 \mu \mathrm{g} / \mathrm{ml}$ showed no inhibitory effect on the ODC activity: D-cycloserine, penicillin $G$, nystatin, polymyxin, 5-fluorocytosine, griseofulvin, mitomycin, kanamycin, streptomycin, tetracycline and antimycin. On the other hand, patulin and penicillic acid strongly inhibited ODC activity. It is interesting to note that penicillic acid was reported to show significant antitumor activities against Ehrlich ascites tumor and leukemia in mice. ${ }^{8)}$ With respect to inorganic salts, addition of $\mathrm{AgNO}_{3}\left(10^{-4} \mathrm{M}\right), \mathrm{HgCl}_{2}\left(10^{-5} \mathrm{M}\right)$ and $\mathrm{KCN}\left(10^{-3} \mathrm{M}\right)$ inhibited the ODC activity significantly in a similar manner as reported for the bacterial ODC. ${ }^{\text {s) }}$

Microbial cultures for the screening were obtained by flask cultures using the medium with the following composition: glucose $1 \%$, Pharmamedia (Traders Co., Texas, U.S.A.) $1 \%$, Ebios $0.25 \%, \mathrm{NaCl} 0.3 \%$, initial pH 6.5. Addition of any component of the medium showed no significant effect on the ODC activity. Nor any significant effect was seen by addition of the culture medium of which the adjusted $\mathrm{pH}$ ranged from 2.0 to 11.0 .

Screening of microbial cultures, 230 Streptomyces and 470 fungal strains, resulted in selection of 18 Streptomyces and 36 fungal strains which strongly inhibited ODC activity. Of these selected microorganisms, the inhibitor produced by the strain identified as Streptomyces neyagawaensis MA-38, was isolated by column chromatography on silica gel. Gas chromatographic analysis of methylated MA-38 showed the presence of 3 components (I, II and III). These 3 components were further separated by silica gel column chromatography. The component I was identified as dihydrosarkomycin methyl ester and II, sarkomycin methyl ester, based on NMR and mass spectral data and physicochemical properties of the purified components. The structure of $\mathrm{III}$ is yet to be determined.

Sarkomycin showed $50 \%$ inhibition (ID 50 ) of ODC at a concentration of $3 \mu \mathrm{g} / \mathrm{ml}$. Studies on the mode 
TABle I. ODC INHIBITION By SARKomyciN, DIHYDROSARKOMYCIN AND THEIR Methyl Esters

\begin{tabular}{crccc}
\hline Final conc. & \multicolumn{2}{c}{ Free form } & \multicolumn{2}{c}{ Methyl ester } \\
$(\mu \mathrm{g} / \mathrm{ml})$ & SK & 2H-SK & SK & 2H-SK \\
\hline 200 & 100 & 95 & 100 & 0 \\
100 & 98 & 86 & 100 & 0 \\
50 & 94 & 69 & 100 & 0 \\
25 & 85 & 33 & 99 & 0 \\
12.5 & 64 & 10 & 97 & 0 \\
\hline
\end{tabular}

SK, sarkomycin; 2H-SK, dihydrosarkomycin.

of sarkomycin inhibition of the enzyme using partially purified preparation by dialysis indicated that the inhibition was noncompetitive with respect to L-ornithine. The inhibitory activities of sarkomycin and the related derivatives against ODC were compared in Table I. Significant increase of activities was observed by methylated sarkomycin $\left(\mathrm{ID}_{50}, 0.85 \mu \mathrm{g} / \mathrm{ml}\right)$, whereas the inhibitory activity of dihydrosarkomycin was lost by methylation. Component III did not show any inhibition of $O D C$.

Sarkomycin is the antitumor antibiotic originally isolated in 1953. ${ }^{8}$ ) The primary site of action was shown to be DNA polymerase. ${ }^{9)}$ Recently, it was also reported to have an anti-phage activity. ${ }^{10)}$ The present finding that sarkomycin strongly inhibits ODC in vitro at lower concentrations compared to inhibition of DNA polymerase suggests a possible role of ODC inhibition in the antitumor activity of sarkomycin in vivo. The present study also showed that ODC inhibition is a useful approach for screening of antitumor agents.

\section{REFERENCES}

1) D. H. Russell and S. H. Snyder, Proc. Natl. Acad. Sci., U.S.A., 60, 1420 (1968).

2) S. H. Snyder, D. S. Kreuz, V. J. Medina and D. H. Russell, Ann. N. Y. Acad. Sci., 171, 749 (1970).

3) D. H. Russell and C. C. Levy, Cancer Res., 31, 248 (1971).

4) D. H. Russell, Am. Assoc. Cancer Res., 11, 69 (1970).

5) H. G. Williams-Ashman, G. L. Coppoc and G. Weber, Cancer Res., 32, 1924 (1972).

6) S. Suzuki, T. Kimura, F. Saito and K. Ando, Agric. Biol. Chem., 35, 287 (1971).

7) E. S. Taylor and E. F. Gale, Biochem. J., 39, 52 (1945).

8) H. Umezawa, T. Takeuchi, K. Nitta, Y. Okami, T. Yamamoto and S. Yamaoka, J. Antibiot., Ser. $A, 6,101$ (1953).

9) S. Sung and J. H. Quastel, Cancer Res., 23, 1549 (1963).

10) M. Koenuma, H. Kinashi and N. Otake, $J$. Antibiot., 27, 801 (1974). 